The following is a pre-publication version of

Andrews, P. \& Sayers, J. (2015) Identifying opportunities for grade one children to acquire foundational number sense: Developing a framework for cross cultural classroom analyses, Early Childhood Education fournal.

DOI: $10.1007 / \mathrm{s} 10643-014-0653-6$

Page numbers will not match those of the published version 


\title{
Identifying opportunities for grade one children to acquire foundational number sense: Developing a framework for cross cultural classroom analyses
}

\author{
Paul Andrews and Judy Sayers, Stockholm University
}

\begin{abstract}
It is known that an appropriately developed foundational number sense (FONS), or the ability to operate flexibly with number and quantity, is a powerful predictor of young children's later mathematical achievement. However, until now not only has FONS been definitionally elusive but instruments for identifying opportunities for children to acquire its various components have been missing from the classroom observation tools available. In this paper, drawing on a constant comparison analysis of appropriate literature, we outline the development of an eight dimensional FONS framework. We then show, by applying this framework to three culturally diverse European grade one lessons, one English, one Hungarian and one Swedish, that it is both straightforwardly operationalised and amenable to cross cultural analyses of classroom practice. Some implications are discussed.
\end{abstract}

\section{Introduction}

Described as a "traditional emphasis in early childhood classrooms" (Casey et al. 2004, 169), number sense is a key objective of many early years' mathematics curricula (Howell and Kemp 2005; Yang and Li 2008). The quality of a child's number sense is a predictor of later mathematical success, both in the short (Aubrey and Godfrey 2003; Aunio and Niemivirta 2010) and the longer term (Aubrey et al. 2006; Aunola et al. 2004). For example, basic counting and enumeration skills have been found to predict arithmetical competence in, inter alia, Canada, England, Finland, Flanders, Taiwan and the USA respectively (LeFevre et al. 2006; Aubrey and Godfrey 2003; Aunola et al. 2004; Desoete et al. 2009; Yang and Li 2008; Jordan et al. 2007). Thus, poorly developed number sense may lead to later mathematical failures (Jordan et al. 2009; Gersten et al. 2005; Malofeeva et al. 2004). Moreover, without appropriate intervention, which can be effective (Van Luit and Schopman 2000; Van Nes and Van Eerde 2010), children who start school with poor number sense are likely to remain low achievers throughout school (Aubrey et al. 2006; Geary 2013). This is important in light of research that number sense acquisition may be linked to a child's family's socio-economic status in general (Melhuish et al. 2008; Starkey et al. 2004) and parental education levels in particular (Ivrendi 2011; Penner and Paret 2008).

\section{What is number sense?}

While understanding the consequences of under-developed number sense is important, research has shown it to be a poorly-defined construct. For example, it has been described as "a person's general understanding of number and operations along with the ability and inclination to use this understanding in flexible ways to make mathematical judgements and to develop useful strategies for handling numbers and operations" (McIntosh et al. 1992, p. 3). Griffin (2004, p. 173), posed and answered her own, rhetorical question. "What is number sense? We all know number sense when we see it but, if asked to define what it is and what it consists of, most of us, including the teachers among us, would have a much more difficult time”.

The definitional uncertainty is compounded by evidence that psychologists and mathematics educators work to different definitions (Berch 2005), a dichotomisation exacerbated by our interpretation of the psychologists' literature, which seems to differ according to whether researchers work in general cognition or learning disabilities. However, 
irrespective of the research tradition, our reading of the literature reveals three distinct but related perspectives. The first, preverbal number sense (Butterworth 2005; Ivrendi 2011; Lipton and Spelke 2005), reflects those number insights that are innate to all humans and comprises an understanding of small quantities in ways that allow for comparison. For example, "6-month-olds can discriminate numerosities with a 1:2 but not a 2:3 ratio, whereas 10-month-old infants also succeed with the latter" (Feigenson et al. 2004, p. 307). Also, children at ages 3 and 4 can estimate accurately the numerosity of sets containing up to five items 9 Gelman and Tucker 1975). Thus, numerical discrimination, which "becomes more precise during infancy" (Lipton and Spelke 2005, p. 978), underpins verbal counting skills (Gallistel and Gelman 2000) and arithmetic (Zur and Gelman 2004). This preverbal number sense is independent of formal instruction, developing as an innate consequence of human, and other species' evolution (Dehaene 2001; Feigenson et al. 2004).

Of course, there are grey areas where the distinction between those elements of number sense that are innate and those that are not are unclear. For example, it has been argued that by age four or five children have normally acquired initial counting skills and an awareness of quantity that allows them to respond to questions about more or less, while by the time they start school children have typically acquired a sense of a mental number line (Aunio et al. 2006; Griffin 2004). However, such number-related understandings are frequently dependent on individual family circumstances (Zur and Gelman 2004), indicating that instruction, whether implicit or explicit, may be necessary for their development. Moreover, as young children from high-socioeconomic status (SES) backgrounds are five times as successful as children from low SES backgrounds on tasks like, which number is bigger, 5 or 4? (Griffin et al. 1994), the case for intervention seems clear, particularly as "aspects of number sense development may be linked to the amount of informal instruction that students receive at home on number concepts” (Gersten et al. 2005, p. 297).

This uncertainty with respect to instruction leads us to our second perspective, which is the explicit focus of this paper. Foundational number sense (FONS), which builds on children's preverbal number sense, comprises those number-related understandings that require instruction and which typically occur during the first years of school (Ivrendi 2011; Jordan and Levine 2009). It is a "construct that children acquire or attain, rather than simply possess” (Robinson et al. 2002, p. 85) and reflects, inter alia, elementary conceptions of number as a representation of quantity or a fixed point in the counting sequence (Griffin 2004).

However, before discussing the details of our emergent perspectives on FONS we present the third perspective, which we have labelled applied number sense and which, in turn, builds on the necessary foundation of FONS. For some writers, this refers to a set of core number-related understandings that permeate all mathematical learning (Faulkner 2009, National Council of Teachers of Mathematics, 1989). More typically, however, applied number sense refers to the "basic number sense which is required by all adults regardless of their occupation and whose acquisition by all students should be a major goal of compulsory education" (McIntosh et al. 1992, p. 3). It reflects a set of understandings and skills that enable a person to

"look at a problem holistically before confronting details, look for relationships among numbers and operations and will consider the context in which a question is posed; choose or invent a method that takes advantage of his or her own understanding of the relationships between numbers or between numbers and operations and will seek the most efficient representation for the given task; use benchmarks to judge number magnitude; and recognize 
unreasonable results for calculations in the normal process of reflecting on answers (Reys 1994, p. 115).

Most number sense-related studies, whether preverbal, foundational or applied, have examined children's competence (See, for example, Aunio and Niemivirta 2010; Chard et al. 2005; Clarke and Shinn 2004; Desoete et al. 2009, 2012; Geary et al. 2009; Holloway and Ansari 2009), with few analysing the number sense-related opportunities that teachers create for their children. In this paper we discuss the development and implementation of a simple to operationalise framework for analysing FONS-related opportunities in different cultural contexts. Such a tool, offering "more refined" and "better operationalized definitions of number sense” is not only necessary but timely (Gersten et al. 2005, p. 302). Such an ambition makes this a unique contribution to the mathematics education literature with the potential to inform teacher education, facilitate classroom evaluations and provide a warranted tool for use in cross-cultural studies of early years' mathematics teaching. But first, we address the literature on FONS in order to synthesis a definition appropriate for our task.

\section{A tentative but concise characterisation of foundational number sense}

It has been argued that FONS is to the development of mathematical competence what phonic awareness is to reading (Gersten and Chard 1999), in that early deficits tend to lead to later difficulties (Jordan et al. 2007; Mazzocco and Thompson 2005). Significantly, it has been shown to be a more robust predictor of later mathematical success than almost any other factor (Aunio and Niemivirta 2010; Byrnes and Wasik 2009). So, what are the characteristics of FONS? Broadly speaking it has been described as the ability to operate flexibly with number and quantity (Aunio et al. 2006; Clarke and Shinn 2004; Gersten and Chard 1999) and can be expressed as attributes like "awareness, intuition, recognition, knowledge, skill, ability, desire, feel, expectation, process, conceptual structure, or mental number line” (Berch 2005, p. 333). Despite such vagueness, some scholars have tried to categorise its characteristic properties. Berch (2005), for example, identified thirty components, Howell and Kemp (2005, 2006) almost thirty and Purpura and Lonigan (2013) twenty-five. Such large numbers, it seems to us, are unlikely to facilitate the development of a framework for identifying FONSrelated learning opportunities that is both simple to operationalise and amenable to crosscultural application.

To facilitate the identification of FONS components we exploited, atypically, the constant comparison analytical approach of the grounded theorists (Glaser and Strauss 1967); an approach appropriate when a new perspective on a construct is being developed from "previously identified possibilities" (Brod et al. 2009, p. 1268). Drawing on mathematics education, psychology, special educational needs and generic education research literature, refereed journal articles and refereed book chapters focused on forms of number sense that were thought by their authors not to be innate were identified. The search was narrowed by the criterion that such components were presented by their authors as applicable to grade one (plus or minus one year) students; that is, students in their first year of formal instruction. This latter criterion acknowledged possible variation in respect of when particular aspects of number sense were thought to be appropriately introduced.

Sources identified in this manner were then read to identify the most widely cited authors. This process, yielded a number of scholars whose articles were selected for immediate analysis. These articles were assigned a random ordering, the first read and an initial categorisation made. This approach, focused on identifying conceptual similarities (Tesch 1990), would have placed, for example, rote counting to five and rote counting to ten, narrow categories discussed by Howell and Kemp (2006), within the same broad category of systematic counting. The second article in the list was then read with two intentions; firstly 
for evidence that would confirm or refine an initial category and secondly for evidence of categorisations not present in the first. Any new categorisations were then tested against articles read earlier. Throughout the analyses, key elements of the constant comparison process, such as the production of memos to record initial thoughts concerning our 'dialogue with the data' (Backman and Kyngäs 1999), were acknowledged. Following the completion of this process, categorical saturation (Brod et al. 2009) was confirmed by an analysis of those articles not included in the first tranche. This process yielded eight categorisations of foundational number sense, each of which we summarise below, supported by as wide a selection of literature is as feasible in a paper such as this.

\section{Number recognition}

FONS-aware children recognise number symbols and know associated vocabulary and meaning (Malofeeva et al. 2004). They can identify a particular number symbol from a collection of number symbols and name a number when shown that symbol (Clarke and Shinn 2004; Gersten et al. 2005; Van de Rijt et al. 1999; Yang and Li 2008). Children who experience difficulty with number recognition tend to experience later mathematical problems (Lemke and Foegen 2009), particularly with subitising (Koontz and Berch 1996; Stock et al. 2010). Alternatively, children who are able to recognise numbers are more able to manage multi-digit arithmetic than those who cannot (Desoete et al. 2012; Krajewski and Schneider 2009). Importantly, such skills are better predictors of later mathematics achievement than either general measures of intelligence or earlier achievement scores (Geary et al. 2009), effects lasting as late as adolescence (Geary et al. 2013).

\section{Systematic counting}

FONS involves systematic counting (Berch 2005; Clarke and Shinn 2004; Gersten et al. 2005; Griffin 2004; Van de Rijt et al. 1999) and includes notions of ordinality and cardinality (Ivrendi 2011; Jordan et al. 2006; LeFevre et al. 2006; Malofeeva et al. 2004; Van Luit and Schopman 2000). It entails counting to twenty and back or counting upwards and backwards from an arbitrary starting point (Jordan and Levine 2009; Lipton and Spelke 2005), knowing that each number occupies a fixed position in the sequence of all numbers (Griffin 2004). Counting skills underpin arithmetical competence in general (Gersten et al. 2005; Passolunghi et al., 2007; Stock et al., 2010) and mental arithmetical competence in particular (Lyons and Beilock 2011).

\section{Awareness of the relationship between number and quantity}

FONS includes an awareness of the relationship between number and quantity. In particular, children understand not only the one-to-one correspondence between a number's name and the quantity it represents but also that the last number in a count represents the total number of objects (Jordan and Levine 2009; Malofeeva et al 2004; Van Luit and Schopman 2000). Significantly, the correspondence between a number's name or symbol and the quantity represented is, essentially, a human invention requiring instruction (Geary 2013). Children who have difficulty with this mapping process tend to experience later mathematical difficulties (Kroesbergen et al. 2009; Mazzocco et al. 2011).

\section{Quantity discrimination}

FONS includes awareness of magnitude and of comparisons between different magnitudes (Clarke and Shinn 2004; Griffin 2004; Ivrendi 2011; Jordan et al. 2006; Jordan and Levine 2009; Yang and Li 2008) and deploys language like bigger than or smaller than (Gersten et al. 2005). Children understand that eight represents a quantity that is bigger than six but smaller than ten (Lembke and Foegen, 2009). In particular, children who are magnitude aware have moved beyond counting as "a memorized list and a mechanical 
routine, without attaching any sense of numerical magnitudes to the words" (Lipton and Spelke 2005, p. 979). Moreover, magnitude awareness has been shown to be a predictor, irrespective of ability or age, of more general mathematical achievement (Aunio and Niemivirta 2010; De Smedt et al. 2013; Desoete et al. 2012; Holloway and Ansari 2009; Nan et al. 2006; Stock et al. 2010).

\section{An understanding of different representations of number}

FONS incorporates an understanding that numbers can be represented differently (Ivrendi 2011; Jordan et al. 2007; Yang and Li 2008) and that these "act as different points of reference" (Van Nes and Van Eerde 2010, p. 146). The better students understand a number line, for example, the higher their later arithmetical achievement (Siegler and Booth 2004; Booth and Siegler 2008). The better a child understands a partition as a representation of a number, the better developed is that child's later understanding of numerical structures (Thomas et al. 2002) and arithmetical skills (Hunting 2003). The more competent a child is with regard to the use of fingers in both counting and early arithmetic, skills that can be taught effectively (Gracia-Bafalluy and Noël 2008), the more competent that child is in later years (Fayol et al. 1998; Jordan et al. 1992; Noël 2005). Significantly, the use of finger strategies increases as socio-economic status increases, justifying targeted interventions (Jordan et al. 1992; Levine et al. 1992) The use of manipulatives, particularly linking blocks, facilitates counting and the identification of errors (Van Nes and Van Eerde 2010). Thus, the better the connections between different representations the more likely a child is to become arithmetically competent (Mundy and Gilmore 2009; Richardson 2004; Van Nes and De Lange 2007, Van Nes and Van Eerde, 2010).

\section{Estimation}

FONS aware children are able to estimate, whether it be the size of a set (Berch 2005; Jordan et al. 2006, 2007; Malofeeva et al. 2004; Van de Rijt et al. 1999) or an object (Ivrendi 2011). Estimation involves moving between representations of number; for example, placing a number on an empty number line (Booth and Siegler 2006). Estimation is thought to be a key determinant of later arithmetical competence, particularly in respect of novel situations (Booth and Siegler 2008; Gersten et al. 2005; Holloway and Ansari 2009; Libertus et al. 2011; Siegler and Booth 2004).

\section{Simple arithmetic competence}

A FONS aware child will be able to perform simple arithmetical operations (Ivrendi 2011; Jordan and Levine 2009; Malofeeva et al. 2004; Yang and Li 2008); skills which underpin arithmetical and mathematical fluency (Berch 2005; Dehaene 2001; Jordan et al. 2007). Indeed, simple arithmetical competence, or the transformation of small sets through addition and subtraction (Jordan and Levine 2009), has been found to be a stronger predictor of later mathematical success than measures of general intelligence (Geary et al. 2009; Krajewski and Schneider 2009). However, drawing on their experiences of combining physical objects, children's ability to solve nonverbal problems develops before the ability to solve comparable word problems (Levine et al. 1992).

\section{Awareness of number patterns}

FONS includes awareness of number patterns and, in particular, being able to identify a missing number (Berch 2005; Clarke and Shinn 2004; Gersten et al. 2005; Jordan et al. 2006, 2007). Such skills reinforce the skills of counting and facilitate later arithmetical operations (Van Luit and Schopman 2000). Importantly, failure to identify a missing number in a sequence is one of the strongest indicators of later mathematical difficulties (Chard et al. 2005; Clarke and Shinn 2004; Gersten et al. 2005; Lemke and Foegen 2009). 
In sum, our analysis of the literature identified eight distinct but not unrelated characteristics of FONS. The fact that they are not unrelated is important as number sense

"relies on many links among mathematical relationships, mathematical principles..., and mathematical procedures. The linkages serve as essential tools for helping students to think about mathematical problems and to develop higher order insights when working on mathematical problems” (Gersten et al. 2005, p. 297).

In other words, without the encouragement of such links there is always the risk that children may be able to count but not undestand, for example, that four is bigger than two.

\section{Evaluating the framework's functionality}

Having derived an eight component framework for analysing FONS-related opportunities, our goal was to examine its functionality as a tool for analysing the learning opportunities offered children in different cultural contexts. This we did by applying it to video-recorded lessons from three different European contexts. It is important to say that none of the analysed lessons was recorded with such an analysis in mind but all proved amenable to one. A number of videotaped lessons were available to us, deriving from various projects to which we have been attached and, of course, public repositories like the TIMSS video study. However, as the FONS framework was developed to analyse, in essence, grade one teaching, selection criteria focused on the following. Firstly, we needed lessons that would prove amenable to such analyses. This may seem evident but lessons focused on, say, geometry would have been less likely to furnish FONS-related evidence. Secondly, a small number of lessons would allow for a deep analysis necessary, privileging quality over quantity. Thirdly, the nature of FONS necessitated grade one lessons, as these represent the first year of formal schooling and the most likely location of FONS-related opportunities. Fourthly, to determine whether the framework's cross-cultural efficacy, it was thought necessary to analyses lessons on a similar topic but from different cultural contexts.

These criteria helped us identify three lessons, which had been video-recorded as part of unrelated projects. All were taught to grade one students and all were focused the properties of number. One derived from an English study of effective primary teachers' beliefs and practices, the second from a study of exemplary Hungarian primary mathematics teaching and the third from a series of Swedish lessons recorded for teacher education purposes. In all cases the teachers concerned, against various local criteria, were well-regarded teachers of mathematics. With respect to data capture, serendipitously similar approaches had been adopted. All teachers were video-recorded in ways that would optimise the capture of their actions and utterances, all had been filmed over several lessons to minimise the likelihood of show-piece lessons and all wore wireless microphones to facilitate optimal coverage of their utterances, both public and private.

As data derived from different projects in three different countries, ethical procedures and permissions were managed according to local norms. In all three countries permission from school principals and participating teachers was obtained by means of letters confirming not only the right of teachers to withdraw without notice or reason but also guarantees of anonymity. With respect to the Hungarian students, all parents, at the point at which their children entered their school, had signed to agree their child's participation in ethically conducted classroom based research. In England and Sweden, parental permission letters were also required. These explained the project and, alongside the promise of minimal classroom disruption, guaranteed the same protective principles as above. No parents refused their child's participation. Finally, the Swedish students were also invited to give their consent, which was discussed orally in the presence of the class teacher. 
All three recordings were supplemented by transcripts of all the utterances made by the teachers and as much students talk as the recordings allowed. The Hungarian and the Swedish lessons were transcribed and translated by Hungarian and Swedish colleagues respectively. Each lesson was viewed repeatedly by at least two but typically all three authors, allowing us to determine which FONS components, as operationalised in table 1, were addressed at what moments. This allowed us to resolve some tensions with respect to operationalisation. For example, we discussed an example whereby a teacher was observed to ask, which numbers are missing from this list; 2, 3, 4, .., 6, 7,.., 9, 10? Would this be categorised as systematic counting or awareness of patterns? Acknowledging the possibility that it could be construed as the former, our view was that the missing numbers classified it as a number patterns question. However, this was one of a very small number of such occasions. On completion of our analyses, our FONS-related interpretations were shared with the colleagues who provided the transcripts to check for authenticity. In the following we present the results of our application of the FONS framework to two successive episodes from each of the three lessons. In so doing, we do not offer any evaluative commentary as our intention was solely to examine the efficacy of the FONS framework as an analytical tool.

\begin{tabular}{|c|c|}
\hline FONS characteristic & Teachers encourage their children to \\
\hline Number recognition & $\begin{array}{l}\text { identify a particular number symbol from a collection of number symbols } \\
\text { and name a number when shown its symbol }\end{array}$ \\
\hline Systematic counting & $\begin{array}{l}\text { count systematically, both forwards and backwards and from arbitrary } \\
\text { starting points }\end{array}$ \\
\hline Relating number to quantity & $\begin{array}{l}\text { understand the one-to-one correspondence between a number's name and the } \\
\text { quantity it represents }\end{array}$ \\
\hline Quantity discrimination & compare magnitudes and deploy language like 'bigger than' or 'smaller than' \\
\hline Different representations & $\begin{array}{l}\text { recognise, work with and make connections between different } \\
\text { representations of number }\end{array}$ \\
\hline Estimation & estimate, whether it be the size of a set or an object \\
\hline Simple arithmetic & perform simple addition and subtraction operations \\
\hline Number patterns & $\begin{array}{c}\text { recognise and extend number patterns and, in particular, identify a missing } \\
\text { number }\end{array}$ \\
\hline
\end{tabular}

Table 1: Working definitions of the eight FoNS components

\section{English episodes}

The lesson began with the teacher, Sarah, placing a 5 x 10 (figure 1) on the interactive whiteboard. This showed the even numbers up to and including 12 shaded red. She asked if anyone could explain the pattern. One child suggested that the shaded numbers ended in 0,2 , 4, 6 or 8, leading Sarah to assert that they were all even. Next she asked about the column patterns and, after another child's suggestion that the numbers in each column end in the same digit, Sarah accepted a different child's idea that the column pattern goes odd even odd. Finally, exploiting the software available to her, she displayed the odd columns in one colour and the even in another. 


\begin{tabular}{|l|l|l|l|l|l|l|l|l|l|}
\hline 1 & 2 & 3 & 4 & 5 & 6 & 7 & 8 & 9 & 10 \\
\hline 11 & 12 & 13 & 14 & 15 & 16 & 17 & 18 & 19 & 20 \\
\hline 21 & 22 & 23 & 24 & 25 & 26 & 27 & 28 & 29 & 30 \\
\hline 31 & 32 & 33 & 34 & 35 & 36 & 37 & 38 & 39 & 40 \\
\hline 41 & 42 & 43 & 44 & 45 & 46 & 47 & 48 & 49 & 50 \\
\hline
\end{tabular}

Figure 1: Sarah's initial whiteboard configuration

In these first few minutes several FONS categories could be construed as having been addressed. For example, the manner in which Sarah accepted a child's suggestion concerning oddness and evenness indicated a focus on number patterns. Also, at least from an implicit perspective, the episode showed an expectation that her children should recognise number symbols and their associated vocabulary and meaning.

Following the completion of this first task, Sarah presented a second $5 \times 10$ grid but this time with no coloured cells. Beneath the grid was written:

$$
1,4,7,10,13 \text {, _ }
$$

She asked her children how they might find the missing numbers. After unproductive prompts Sarah tapped, in turn, each of the five numbers to change their colour to red (figure 2). She commented that the grid now looked different from the earlier one and asked have I done it wrong? Different students offered, hesitantly, both positive and negative responses, which elicited no comment from Sarah.

\begin{tabular}{|l|l|l|l|l|l|l|l|l|l|}
\hline 1 & 2 & 3 & 4 & 5 & 6 & 7 & 8 & 9 & 10 \\
\hline 11 & 12 & 13 & 14 & 15 & 16 & 17 & 18 & 19 & 20 \\
\hline 21 & 22 & 23 & 24 & 25 & 26 & 27 & 28 & 29 & 30 \\
\hline 31 & 32 & 33 & 34 & 35 & 36 & 37 & 38 & 39 & 40 \\
\hline 41 & 42 & 43 & 44 & 45 & 46 & 47 & 48 & 49 & 50 \\
\hline
\end{tabular}

Figure 2: Sarah's second whiteboard configuration

Next, Luke raised his hand and the following ensued:

Sarah Luke?

Luke Sixteen

Sarah Why sixteen?

Luke Because you're adding on three

Sarah Because it's adding on three isn't it (she tapped the cell to change the colour)...

What's going to be the next one? Isla?

Isla Nineteen

Sarah What's going to be the next one? Ian?

Ian Twenty-two

Sarah Twenty-two (she tapped the cell). And the next one? (many hands are now raised) Rachel?

Rachel Twenty-five (she tapped the cell, which became red).

In this short episode can be seen further evidence of Sarah's encouraging different aspects of FONS. The four students involved in the public exchanges were extending the sequence with confidence, fully aware, it seems to us, of the constant addition of three. Indeed, Luke's assertion that they were adding on three, followed by the three other successful contributions indicated an engagement with simple arithmetical operations. Finally, 
Sarah's children were still being made aware of the relationship between symbols, their vocabulary and meaning.

\section{Hungarian episodes}

Klara, the teacher, began her lesson with the configuration shown in figure 3 having been written on the board prior to the lesson's start.

$$
3
$$

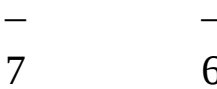

$$
10
$$

Figure 3: Klara’s initial configuration

On her invitation and with Klara pointing to each in number in turn, the class read out the numbers in unison. Next, moving from left to right, she invited volunteers to explain how each number might be derived from the one preceding it. Students volunteered that the first jump was add four, then subtract one and add four. With each offering Klara wrote the operation underneath, as shown in figure 4.

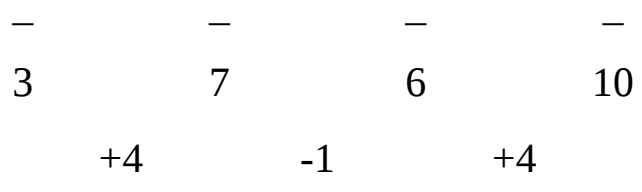

Figure 4: The configuration after initial suggestions concerning operations

Klara then asked what her students thought would be the next operation, which led to their suggesting that it would be to subtract one. Klara added this to the table before eliciting from the class that the result of this process would be nine, which was also added to the table. This process was repeated until the table was completed, as in figure 5.

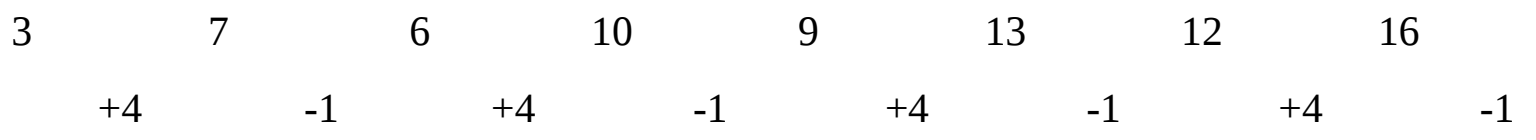

Figure 5: The completed sequence

During this period Klara encouraged several categories of FONS. Firstly, the lesson, which began with children being invited to recognise and read the numbers on the board, was focused on the recognition of number symbols and their vocabulary. It could also be inferred that she was encouraging them to attribute meaning to both symbols and words. Secondly, in the ways in which successive numbers were identified, Klara encouraged an engagement with simple arithmetical operations. Thirdly, the episode entailed an activity focused on number patterns and the ways in which knowledge of the embedded relationships can identify missing numbers.

On completion of this task, Klara showed the class a set of cards, each of which had a letter written on it. She announced that they were going to play a game, which involved her asking questions to which the answer would be one of the numbers in the sequence. Each correct answer would yield a letter that will eventually spell out a word that would tell the class where it would be going in the story of this particular day ${ }^{1}$. Klara asked a different form of question for each of the numbers in the sequence. For example, I am thinking of the largest

\footnotetext{
${ }^{1}$ Typically, Klara located everything she taught within a narrative or story for the day
} 
one digit number, a number two smaller than nine, the largest two digit number, the smallest one digit number, a number whose digits add up to 4, and so on. In each case at least one child was involved in responding to the question posed and with each correct response a new letter was attached to the board. Eventually, as shown in figure 6, the word was almost complete, with only a single letter missing. At this point, Klara invited her students to offer statements appropriate to that number, which led to six suggestions similar to the forms of question she had already asked before, finally, the letter $\mathrm{SZ}^{2}$ was added to give the word, bábszínház (puppet theatre).

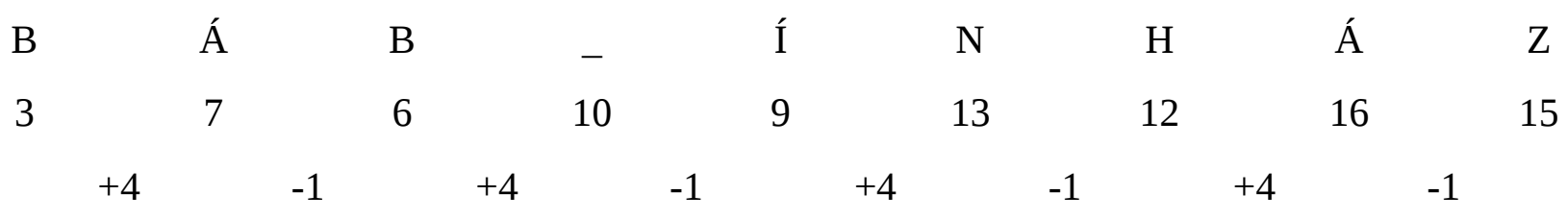

Figure 6: The nearly complete configuration

Several FONS-related categories could be inferred from this episode. Indeed, every statement could be construed as focusing on different representations of number in the sense, for example, that a number two smaller than nine is a different representation of seven. Simple arithmetical operations were addressed by the same statement as well as thirteen being presented as a number whose digits sum to four. Awareness and comparisons of magnitude were addressed in statements like the largest two digit or smallest one digit number and so on.

Swedish episodes

Each child, having been given a small bowl containing six small pebbles, was asked by Kerstin, the teacher, to take all six pebbles and place them into two distinct groups. While they did this, Kerstin drew a line down the middle of the board to create two halves. She then wrote six at the top and invited students to offer, in essence, different sums to six. The first child volunteered three and three. At this point, Kerstin fixed three disks to one side of her line and three to the other.

The process continued, a second child suggested two and four, which Kerstin placed above the previous contribution. A third child suggested five and one, and it now became clear that Kerstin was placing her counters so that each ordered pair had a well-defined place on her board, with left 0 , right 6 at the top down to left six, right zero at the bottom. The next four students offered six and zero, four and two, zero and six, and one and five respectively. In this manner, seven sets of counters were placed systematically on the board, with each pair, representing a pair of integers summing to six. At this stage Kerstin drew a horizontal line across the board to separate each pair, as shown in figure 7. Finally, in this episode, Kerstin encouraged her children to count, together, down the left hand side and then up the right hand side of her diagram. As she placed her counters on the board, Kerstin highlighted, albeit implicitly, several mathematical insights. Firstly, she represented each number by two columns of counters arranged so that an odd number was always the previous even with an additional counter above. Secondly, she highlighted zero as a significant contributor to the partitioning, a role which emerged from her children. Thirdly, her ordering of the different partitions highlighted the symmetrical relationship in the partitions.

In this episode can be seen several FONS categories. Firstly, the use of pebbles reminded children that numbers represent quantities. Secondly, the partitions presented on the board could be construed as different representations of six. Thirdly, although no number symbols were used, Kerstin encouraged her students to use the vocabulary of number

\footnotetext{
${ }^{2}$ In Hungarian sz is an alphabetic letter pronounced like s in the English word sun.
} 
throughout the episode, linking number names to the various configurations of pebbles and counters. Fourthly, if only implicitly, the act of partitioning encouraged children to engage with simple addition. Fifthly, the manner in which Kerstin arranged the solutions on the board highlighted two forms of number pattern. On the one hand there was the clear distinction between even and odd integers, although, of course, this could also be construed as another perspective on the representation of numbers. On the other hand, the sequencing of the solutions highlighted the fact that as one set of numbers decreases, the other increases. Sixthly, the arrangement of the partitions could be construed as an encouragement for children to see numbers as having well ordered places in the sequence of all numbers, which, alongside the final act of the episode, could be construed as facilitating counting competence.

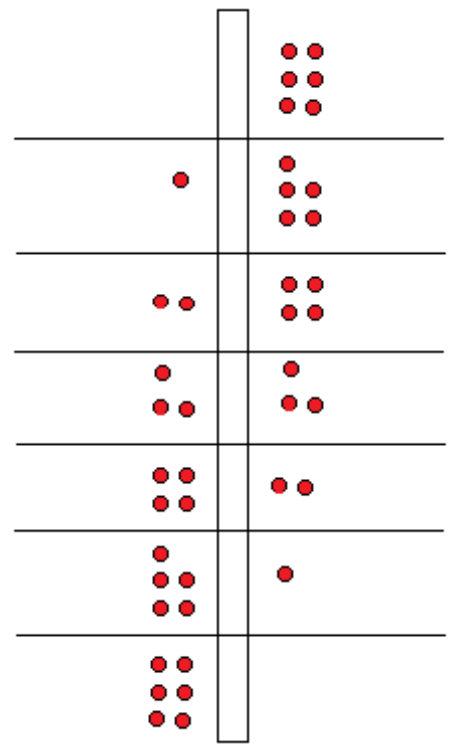

Figure 7: Kerstin’s configuration of counters

Next Kerstin invited the class to play a game in pairs. One child held the six pebbles behind his or her back in order to distribute them secretly between two hands. He or she would then reveal one hand's contents in order that the second child could say what was in the closed hand. Each pair would then swap roles and repeat the process, creating many opportunities for children to rehearse the partitions of and complements to six.

With respect to FONS-related opportunities, the game allowed children to consolidate links between number vocabulary and the different configurations of pebbles, the connection between number and quantity, to engage with different representations of number and, implicitly, to exploit simple arithmetic or counting to locate the missing number.

\section{Discussion}

In this paper we set out to derive and evaluate a framework for identifying opportunities for children to acquire foundational number sense (FONS). Our aims were that the framework should adequately represent the FONS construct, be simple to operationalise, and provide an efficacious tool for evaluating FONS-related opportunities in different cultural contexts.

With respect to the first of those aims, the eight categories of FONS-related learning outcomes have a self-evidence, which many readers may recognise, that alludes to face validity. That is, each reflects a characteristic of number sense with which, we believe, few readers will disagree. However, face validity alone is an insufficient warrant; in terms resonant with the traditions of quantitative research, content validity should be the goal. But 
we have not undertaken a quantitative study; we have undertaken an atypical constant comparison analysis of the literature pertaining to foundational number sense. That is, drawing on articles as data, we undertook a systematic qualitative analysis of others' perspectives on the construct. So, what evidence can we present in support of our claims for content validity? Firstly, unlike some studies, in which authors have failed to articulate their analytical approaches adequately, our clear articulation of and adherence to the constant comparison method should not only facilitate reader confidence in our results but overcome concerns relating to the bias frequently associated with constant comparison analyses (Brod et al. 2009). Secondly, the achievement of categorical saturation, in accordance with the principles and process of constant comparison (Wasserman et al. 2009), should warrant both the credibility and the authenticity (LeCompte and Preissle Goetz 1982) of the eight FONSrelated categories.

With respect to the second and third aims, the analyses of three culturally different lessons confirm not only that the framework is straightforwardly operationalised but efficacious in different cultural contexts. we have been successful. Admittedly, in none of the reported lessons were teachers observed to encourage students to estimate either the size of a set or object, but the remaining seven characteristics of the FONS framework were observed in, we argue, unambiguous and straightforward ways. Moreover, as not one of the lessons was explicitly focused on the development of FONS, the framework has shown itself to be sensitive to the identification of incidental teaching (Radwan 2005).

Finally, the eight FONS components appear not only to have overcome the definitional vagueness criticised by earlier scholars (Gersten et al. 2005; Griffin 2004) but overcome the lengthy and largely cumbersome lists of Berch (2005), Howell and Kemp (2005, 2006) and Purpura and Lonigan (2013). Moreover, the construct validity discussed above may warrant the FONS components as an underlying curricular framework for both learners in schools and students following teacher education programmes. This latter point is particularly important when one considers the extent to which much published research in mathematics education or psychology, say, has too little immediate transferability or relevance to the lived realities of teachers' classrooms (Arbaugh et al. 2010). However, the next phase of our work will be to test the framework on representative samples of lessons from different cultural contexts in order to understand better how different systems underpin learners' acquisition of FONS competence.

\section{References}

Arbaugh, F., Herbel-Eisenmann, B., Ramirez, N., Knuth, E., Kranendonk, H., \& Reed Quander, J. (2010). Linking research and practice: The NCTM research agenda conference report. Reston VA: NCTM.

Aubrey, C., \& Godfrey, R. (2003). The development of children's early numeracy through key stage 1. British Educational Research Journal, 29(6), 821-840.

Aubrey, C., Dahl, S., \& Godfrey, R. (2006). Early mathematics development and later achievement: Further evidence. Mathematics Education Research Journal, 18(1), 27-46.

Aunio, P., Niemivirta, M., Hautamäki, J., Van Luit, J., Shi, J., \& Zhang, M. (2006). Young children's number sense in China and Finland. Scandinavian Journal of Educational Research, 50(5), 483-502.

Aunio, P., \& Niemivirta, M. (2010). Predicting children's mathematical performance in grade one by early numeracy. Learning and Individual Differences, 20(5), 427-435. 
Aunola, K., Leskinen, E., Lerkkanen, M.-K., \& Nurmi, J.-E. (2004). Developmental dynamics of math performance from preschool to grade 2. Journal of Educational Psychology, 96(4), 699-713.

Backman, K., \& Kyngäs, H. A. (1999). Challenges of the grounded theory approach to a novice researcher. Nursing \& Health Sciences, 1(3), 147-153.

Berch, D. (2005). Making sense of number sense. Journal of Learning Disabilities, 38(4), 333-339.

Booth, J., \& Siegler, R. (2006). Developmental and individual differences in pure numerical estimation. Developmental Psychology, 42(1), 189-201.

Booth, J., \& Siegler, R. (2008). Numerical magnitude representations influence arithmetic learning. Child Development, 79(4), 1016-1031.

Brod, M., Tesler, L., \& Christensen, T. (2009). Qualitative research and content validity: Developing best practices based on science and experience. Quality of Life Research, 18(9), 1263-1278.

Butterworth, B. (2005). The development of arithmetical abilities. Journal of Child Psychology and Psychiatry, 46(1), 3-18.

Byrnes, J., \& Wasik, B. (2009). Factors predictive of mathematics achievement in kindergarten, first and third grades: An opportunity-propensity analysis. Contemporary Educational Psychology, 34(2), 167-183.

Casey, B., Kersh, J., \& Young, J. (2004). Storytelling sagas: An effective medium for teaching early childhood mathematics. Early Childhood Research Quarterly, 19(1), 167-172.

Chard, D., Clarke, B., Baker, S., Otterstedt, J., Braun, D., \& Katz, R. (2005). Using measures of number sense to screen for difficulties in mathematics. Assessment for Effective Intervention, 30(2), 3-14.

Clarke, B., \& Shinn, M. (2004). A preliminary investigation into the identification and development of early mathematics curriculum-based measurement. School Psychology Review, 33(2), 234-248.

Dehaene, S. (2001). Précis of the number sense. Mind \& Language, 16(1), 16-36.

Desoete, A., Stock, P., Schepens, A., Baeyens, D., \& Roeyers, H. (2009). Classification, seriation, and counting in grades 1,2 , and 3 as two-year longitudinal predictors for low achieving in numerical facility and arithmetical achievement? Journal of Psychoeducational Assessment, 27(3), 252-264.

Desoete, A., Ceulemans, A., De Weerdt, F., \& Pieters, S. (2012). Can we predict mathematical learning disabilities from symbolic and non-symbolic comparison tasks in kindergarten? Findings from a longitudinal study. British Journal of Educational Psychology, 82(1), 64-81.

De Smedt, B., Noël, M.-P., Gilmore, C., \& Ansari, D. (2013). How do symbolic and nonsymbolic numerical magnitude processing skills relate to individual differences in children's mathematical skills? A review of evidence from brain and behavior. Trends in Neuroscience and Education, 2(2), 48-55.

Faulkner, V. (2009). The components of number sense. Teaching Exceptional Children, 41(5), 24-30.

Fayol, M., Barrouillet, P., \& Marinthe, C. (1998). Predicting arithmetical achievement from neuro-psychological performance: a longitudinal study. Cognition, 68(2), B63-B70. 
Feigenson, L., Dehaene, S., \& Spelke, E. (2004). Core systems of number. Trends in Cognitive Sciences, 8(7), 307-314.

Gallistel, C., \& Gelman, R. (2000). Non-verbal numerical cognition: From reals to integers. Trends in Cognitive Sciences, 4(2), 59-65.

Geary, D. (2013). Early foundations for mathematics learning and their relations to learning disabilities. Current Directions in Psychological Science, 22(1), 23-27.

Geary, D. Bailey, D., \& Hoard, M. (2009). Predicting mathematical achievement and mathematical learning disability with a simple screening tool. Journal of Psychoeducational Assessment, 27(3), 265-279.

Gelman, R., \& Tucker, M. (1975). Further investigations of the young child's conception of number. Child Development, 46(1), 167-175.

Gersten, R., \& Chard, D. (1999). Number sense: Rethinking arithmetic instruction for students with mathematical disabilities. The Journal of Special Education, 33(1), 18-28.

Gersten, R., Jordan, N., \& Flojo, J. (2005). Early identification and interventions for students with mathematics difficulties. Journal of Learning Disabilities, 38(4), 293-304.

Glaser, B., \& Strauss, A. (1967). The discovery of grounded theory: strategies for qualitative research. New York: Aldine.

Gracia-Bafalluy, M., \& Noël, M.-P. (2008). Does finger training increase young children's numerical performance? Cortex, 44(4), 368-375.

Griffin, S. (2004). Building number sense with Number Worlds: A mathematics program for young children. Early Childhood Research Quarterly, 19(1), 173-180.

Griffin, S., Case, R., \& Siegler, R. (1994). Rightstart: Providing the central conceptual prerequisites for first formal learning of arithmetic to students at risk for school failure. In K. McGilly (Ed.), Classroom lessons: Integrating cognitive theory and classroom practice (pp. 24-49). Cambridge, MA: MIT Press.

Holloway, I., \& Ansari, D. (2009). Mapping numerical magnitudes onto symbols: The numerical distance effect and individual differences in children's mathematics achievement. Journal of Experimental Child Psychology, 103(1), 17-29.

Howell, S., \& Kemp, C. (2005). Defining early number sense: A participatory Australian study. Educational Psychology, 25(5), 555-571.

Howell, S., \& Kemp, C. (2006). An international perspective of early number sense: Identifying components predictive of difficulties in early mathematics achievement. Australian Journal of Learning Disabilities, 11(4), 197-207.

Hunting, R. (2003). Part-whole number knowledge in preschool children. The Journal of Mathematical Behavior, 22(3), 217-235.

Ivrendi, A. (2011). Influence of self-regulation on the development of children's number sense. Early Childhood Education Journal, 39(4), 239-247.

Jordan, N.., \& Levine, S. (2009). Socioeconomic variation, number competence, and mathematics learning difficulties in young children. Developmental Disabilities Research Reviews, 15(1), 60-68.

Jordan, N., Huttenlocher, J., \& Levine, S. (1992). Differential calculation abilities in young children from middle- and low-income families. Developmental Psychology, 28(4), 644653. 
Jordan, N., Kaplan, D., Nabors Oláh, L., \& Locuniak, M. (2006). Number sense growth in kindergarten: A longitudinal investigation of children at risk for mathematics difficulties. Child Development, 77(1), 153-175.

Jordan, N., Kaplan, D., Locuniak, M., \& Ramineni, C. (2007). Predicting first-grade math achievement from developmental number sense trajectories. Learning Disabilities Research \& Practice, 22(1), 36-46.

Jordan, N., Kaplan, D., Ramineni, C., \& Locuniak, M. (2009). Early math matters: Kindergarten number competence and later mathematics outcomes. Developmental Psychology, 45(3), 850-867.

Koontz, K., \& Berch, D. (1996). Identifying simple numerical stimuli: Processing inefficiencies exhibited arithmetic learning disabled children. Mathematical Cognition, 2(1), 1-23.

Krajewski, K., \& Schneider, W. (2009). Early development of quantity to number-word linkage as a precursor of mathematical school achievement and mathematical difficulties: Findings from a four-year longitudinal study. Learning and Instruction, 19(6), 513-526.

Kroesbergen, E., Van Luit, J., Van Lieshout, E., Van Loosbroek, E., \& Van de Rijt, B. (2009). Individual differences in early numeracy. Journal of Psychoeducational Assessment, 27(3), 226-236.

LeCompte, M., \& Goetz Preissle, J. (1982). Problems of reliability and validity in ethnographic research. Review of Educational Research, 52(1), 31-60.

LeFevre, J.-A., Smith-Chant, B., Fast, L., Skwarchuk, S.-L., Sargla, E., Arnup, J. et al. (2006). What counts as knowing? The development of conceptual and procedural knowledge of counting from kindergarten through Grade 2. Journal of Experimental Child Psychology, 93(4), 285-303.

Lembke, E., \& Foegen, A. (2009). Identifying early numeracy indicators for kindergarten and first-grade students. Learning Disabilities Research \& Practice, 24(1), 12-20.

Levine, S., Jordan, N., \& Huttenlocher, J. (1992). Development of calculation abilities in young children. Journal of Experimental Child Psychology, 53(1), 72-103.

Libertus, M., Feigenson, L., \& Halberda, J. (2011). Preschool acuity of the approximate number system correlates with school math ability. Developmental Science, 14(6), 1292-1300.

Lipton, J., \& Spelke, E. (2005). Preschool children's mapping of number words to nonsymbolic numerosities. Child Development, 76(5), 978-988.

Lyons, I., \& Beilock, S. (2011). Numerical ordering ability mediates the relation between number-sense and arithmetic competence. Cognition, 121(2), 256-261.

Malofeeva, E., Day, J., Saco, X., Young, L., \& Ciancio, D. (2004). Construction and evaluation of a number sense test with Head Start children. Journal of Educational Psychology, 96(4), 648-659.

Mazzocco, M., \& Thompson, R. (2005). Kindergarten predictors of math learning disability. Learning Disabilities Research and Practice, 20(3), 142-155.

Mazzocco, M., Feigenson, L., \& Halberda, J. (2011). Impaired acuity of the approximate number system underlies mathematical learning disability (dyscalculia). Child Development, 82(4), 1224-1237. 
McIntosh, A., Reys, B., \& Reys, R. (1992). A proposed framework for examining basic number sense. For the Learning of Mathematics, 12(3), 2-8.

Melhuish, E., Sylva, K., Sammons, P., Siraj-Blatchford, I., Taggart, B., Phan, M., \& Malin, A. (2008). Preschool influences on mathematics achievement. Science, 321, 1161-1162.

Mundy, E., \& Gilmore, C. (2009). Children's mapping between symbolic and nonsymbolic representations of number. Journal of Experimental Child Psychology, 103(4), 490-502.

Nan, Y., Knösche, T., \& Luo, Y.-J. (2006). Counting in everyday life: Discrimination and enumeration. Neuropsychologica, 44(7), 1103-1113.

National Council of Teachers of Mathematics (1989). Curriculum and evaluation standards for school mathematics. Reston: NCTM.

Noël, M.-P. (2005). Finger gnosia: A predictor of numerical abilities in children? Child Neuropsychology, 11(5), 413-430.

Passolunghi, M., Vercelloni, B., \& Schadee, H. (2007). The precursors of mathematics learning: Working memory, phonological ability and numerical competence. Cognitive Development, 22(2), 165-184.

Penner, A., \& Paret, M. (2008). Gender differences in mathematics achievement: Exploring the early grades and the extremes. Social Science Research, 37(1), 239-253.

Purpura, D., \& Lonigan, C. (2013). Informal numeracy skills: The structure and relations among numbering, relations, and arithmetic operations in preschool. American Educational Research Journal, 50(1), 178-209.

Radwan, A. (2005). The effectiveness of explicit attention to form in language learning. System, 33(1), 69-87.

Reys, B. (1994). Promoting number sense in the middle grades. Mathematics Teaching in the Middle School, 1(2), 114-120.

Richardson, K. (2004). Making sense. In D. Clements \& J. Sarama (Eds.), Engaging young children in mathematics: Standards for early childhood mathematics (pp. 321-324). Mahwah: Erlbaum.

Robinson, C., Menchetti, B., \& Torgesen. J. (2002). Toward a two-factor theory of one type of mathematics disabilities. Learning Disabilities Research \& Practice, 17(2), 81-89.

Siegler, R., \& Booth, J. (2004). Development of numerical estimation in young children. Child Development, 75(2), 428-444.

Starkey, P., Klein, A., \& Wakeley, A. (2004). Enhancing young children's mathematical knowledge through a pre-kindergarten mathematics intervention. Early Childhood Research Quarterly, 19(1), 99-120.

Stock, P., Desoete, A., \& Roeyers, H. (2010). Detecting children with arithmetic disabilities from kindergarten: Evidence from a 3-year longitudinal study on the role of preparatory arithmetic abilities. Journal of Learning Disabilities, 43(3), 250-268.

Tesch, R. (1990). Qualitative research: Analysis types and software tools. New York: Falmer.

Thomas, N., Mulligan, J., \& Goldin, G. (2002). Children's representation and structural development of the counting sequence 1-100. The Journal of Mathematical Behavior, 21(1), 117-133. 
Van de Rijt, B., Van Luit, J., \& Pennings, A. (1999).The construction of the Utrecht early mathematical competence scale. Educational and Psychological Measurement, 59(2), 289-309.

Van Luit, J., \& Schopman, E. (2000). Improving early numeracy of young children with special educational needs. Remedial and Special Education, 21(1), 27-40.

Van Nes, F., \& De Lange, J. (2007). Mathematics education and neurosciences: Relating spatial structures to the development of spatial sense and number sense. The Montana Mathematics Enthusiast, 2(4), 210-229.

Van Nes, F., \& Van Eerde, D. (2010). Spatial structuring and the development of number sense: A case study of young children working with blocks. The Journal of Mathematical Behavior, 29(2), 145-159.

Wasserman, J., Clair, J., \& Wilson, K. (2009). Problematics of grounded theory: innovations for developing an increasingly rigorous qualitative method. Qualitative Research, 9(3), 355-381.

Yang, D.-C., \& Li, M.-N. (2008). An investigation of 3rd-grade Taiwanese students' performance in number sense. Educational Studies, 34(5), 443 - 455.

Zur, O., \& Gelman, R. (2004). Young children can add and subtract by predicting and checking. Early Childhood Research Quarterly, 19(1), 121-137. 